\title{
Mondor's disease associated with metastatic lung cancer in the breast
}

\author{
S.P. Courtney, ${ }^{1}$ S. Polacarz ${ }^{2}$ and A.T. Raftery ${ }^{1}$
}

Department of ${ }^{1}$ Surgery (Ifloor) and ${ }^{2}$ Pathology, Royal Hallamshire Hospital, Glossop Road, Sheffield, S10 2JF, $U K$.

\begin{abstract}
Summary: We report what we believe is the first recorded case of Mondor's disease associated with metastatic lung cancer presenting in the breast. An association between Mondor's disease and primary breast cancer has been described previously. In patients with Mondor's disease the possibility of underlying carcinoma, either primary or secondary, must be considered.
\end{abstract}

\section{Introduction}

Mondor's disease is an uncommon condition of the breast. ${ }^{1}$ The clinical features are of tenderness in the breast associated with the development of a palpable, linear, cord-like swelling, which often appears branched. There is thrombosis of the lateral thoracic vein, with perivenous fibrosis which causes bow stringing of the vessel. Microscopically, at 2 weeks there is thrombus within the vein and at 4 weeks thickening of the vein wall and a fibrous plug. The condition is usually 'burnt out' by 6 weeks. ${ }^{2}$ The aetiology is unknown but patients often give a history of local trauma or muscular strain. ${ }^{2,3}$

Mondor's disease has also been reported in association with primary breast cancer. ${ }^{4,5}{ }^{-}$Hogan $^{6}$ suggests the pathophysiological basis in Mondor's disease is due to pressure on the lateral thoracic veins or results from direct trauma. We report a case of Mondor's disease associated with metastatic lung cancer presenting in the breast.

\section{Case report}

A married woman, 59 years old, was seen in the surgical clinic complaining of pain and a tender cord-like swelling in the upper outer quadrant of the left breast. There was no history of trauma or excessive muscular effort preceding the appearance of the lesion. She smoked 10 cigarettes a day.

On examination a cord-like tender swelling was noted running along the lateral border of the left breast, arising near the lateral end of the clavical and ending just above the nipple. No discreet lumps were

Correspondence: A.T. Raftery F.R.C.S

Accepted: 30 March 1989 palpable within either breast but three small (less than $1 \mathrm{~cm})$ mobile rubbery nodes were palpable in the left axilla. A mammogram showed no abnormality. The patient was reviewed 6 weeks later and on this occasion peau d'orange was noted in the lower medial quadrant of the left breast. No breast mass was palpable. Axillary lymphadenopathy remained but in addition a node $0.5 \mathrm{~cm}$ in diameter was palpable in the left supraclavicular fossa. The tender cord had now disappeared. A provisional diagnosis of primary carcinoma of the breast with metastases was made, the patient started on tamoxifen, and arrangements made for admission for open biopsy. On admission 2 weeks later, clinical examination revealed a $2.5 \mathrm{~cm}$ diameter mass in the left breast inferior to nipple, the axillary nodes were larger and the supraclavicular node was now $1 \mathrm{~cm}$ in diameter. A chest X-ray showed a $2 \mathrm{~cm}$ diameter lesion at the apex of the right lung and further views with screening of the right apex confirmed the lesion as intrapulmonary and demonstrated bilateral hilar lymphadenopathy. Open biopsy of the breast lesion and axillary nodes was performed.

Histological examination showed a well demarcated tumour mass composed of sheets of large pleomorphic tumour cells in which mitoses and necrosis were prominent. The appearances were considered atypical for a primary mammary carcinoma, and a diagnosis of metastatic carcinoma suggested. Electron microscopy subsequently demonstrated dense-core neurosecretory granules within tumour cells (Figure 1), and these findings strongly supported a diagnosis of a metastatic lesion in the breast, with an oat cell carcinoma of the lung representing the primary lesion. The patient subsequently developed confusion, euphoria, occipital headache and incontinence. A CT scan performed at this time showed multiple cerebral 


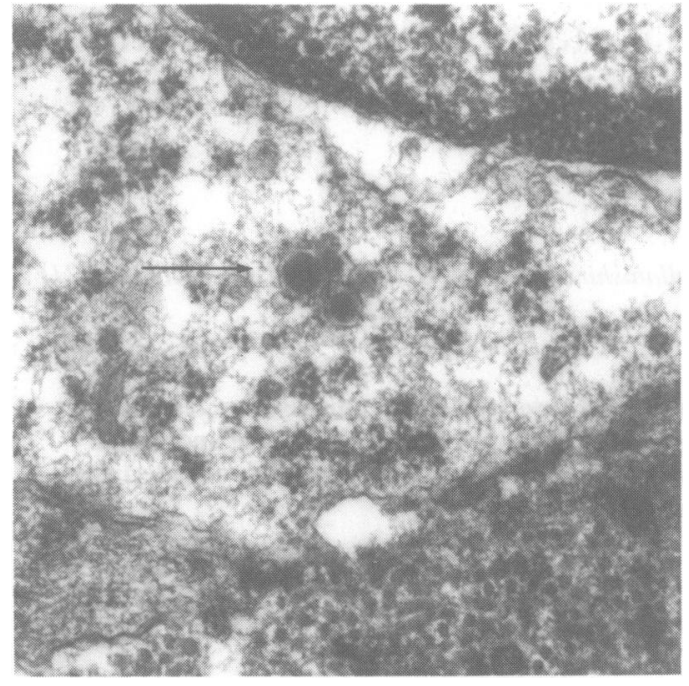

Figure 1 Tumour cells containing dense-core neurosecretory granules (arrow). Magnification $\times 15$, 600.

\section{References}

1. Mondor, H. Tronculite sours-coutanée subaiguë de la paroi thoracique antérolatérale. Mém Acad Chir 1939, 65: $1271-1278$.

2. Haagensen, C.D. Thrombophlebitis of the superficial veins of the breast (Mondor's disease). In: Haagensen, C.D. (ed) Diseases of the Breast. W.B. Saunders Co, Philadelphia, 1986, pp. 379-382.

3. Musgrove, J.E. Subcutaneous phlebitis of the breast (Mondor's disease). Can Med Assoc J 1961, 85: 34-37.

4. Levi, I. \& Baum, M. Mondor's disease as a presenting symptom of breast cancer. Br J Surg 1987, 74: 700.

5. Farrow, J.H. Thrombophlebitis of the superficial veins of the breast and anterior chest wall (Mondor's disease). Surg Gynecol Obstet 1955, 101: 63-68. metastases. The patient's condition deteriorated and she died 3 weeks after her admission. Permission for post-mortem was not obtained.

\section{Discussion}

The association of Mondor's disease and breast cancer has been previously described. ${ }^{4,7}$ In addition Miller $e t$ $a l^{8}{ }^{8}$ reported a case where ipsilateral thrombophlebitis heralded recurrent axillary metastasis from a breast carcinoma. In our patient the thrombophlebitis was the presenting feature of a highly aggressive, metastatic, oat cell carcinoma of the lung. Oat cell carcinoma is the commonest primary to metastasize to the breast. ${ }^{9}$ It may be that the thrombophlebitis was a manifestation of Trousseau's sign (migratory thrombophlebitis) but no other manifestations of this occurred. We believe this to be the first recorded case of Mondor's disease associated with metastatic carcinoma in the breast. In patients presenting with Mondor's disease, the possibility of underlying carcinoma, either primary or secondary, must be considered.

6. Hogan, G.F. Mondor's disease. Arch Intern Med 1964 113: $881-885$.

7. Lunn, G.M. \& Potter, J.M. Mondor's disease (subcutaneous phlebitis of the breast region). $\mathrm{Br} M e d J$ 1954, 1: 1074-1076.

8. Miller, D.R., Cesaria, T.C. \& Slater, L.M. Mondor's disease associated with metastic axillary nodes. Cancer 1985, 56: 903-904.

9. Kelly, C., Henderson, D. \& Corris, P. Breast lumps: rare presentation of oat cell carcinoma of the lung. $J$ Clin Pathol 1988, 41: 171-172. 